\title{
Vascular aging processes accelerate following a cubic kinetic: pulse wave velocity as an objective counterpart that time, as we age, goes by faster
}

This article was published in the following Dove Press journal:

Clinical Interventions in Aging

\author{
Luca Gabutti \\ Rosaria Del Giorno \\ Department of Internal Medicine \\ and Nephrology, Bellinzona Regional \\ Hospital, Bellinzona, Switzerland
}

\section{Introduction}

Arterial stiffness is a marker of vascular aging and is considered to be the most reliable parameter expressing, like an integral in mathematics, the cumulative consequences, on the vascular wall, of degenerative and adaptive changes occurring throughout life. ${ }^{1}$ The efficiency of the reparative processes, the cardiovascular risk factors (CVRF), and early life and genetic determinants, all play a relevant role. ${ }^{1}$ Among CVRF, the acceleration in arterial stiffness progression related to age is mainly influenced by hypertension. ${ }^{1}$ A pathological acceleration translates into the concept of early vascular aging, a concept that can be quantified calculating the gap between the subject's chronological (estimated on the basis of the epidemiological data obtained in the normal population) and effective vascular age. ${ }^{2}$ Data of subpopulations without active risk factors for accelerated vascular aging can be found mainly in three large epidemiological studies, performed respectively in Portugal, ${ }^{3}$ Argentina, ${ }^{4}$ and seven different European countries (Belgium, Czech Republic, France, Greece, Italy, the Netherlands, and UK) gathered in a collaborative investigation. ${ }^{5}$ Those doing this secondary analysis were aware of the limitation related to the use of cross-sectional data to extrapolate longitudinal changes, and their aims were combining the abovementioned epidemiological data concerning the normal population to calculate with the highest possible accuracy 1) the age-related increase in acceleration of the pulse wave velocity (PWV) and to estimate both 2) the age-specific relative amount of time equivalent to that necessary to progress 1 year in vascular age at 20, and 3) the cumulative relative age calculated in year equivalents.

\section{Methods}

The published epidemiological PWV data, referring to to three subpopulations without classical CVRF for an early vascular aging, ${ }^{3-5}$ were combined, respecting the original age groups, using a weighted mean. Considering the limited sample size and the dispersion of the data in $>70$-year olds, the analysis was restricted to subjects between 20 and 69 years of age. Linear and polynomial (second and third degree) models were then built with the aim of choosing the function fitting the pooled data with the highest accuracy. The obtained $R^{2}$, standard deviation of the residuals, and $p$-values were as follows: $0.947,0.341,<0.001 ; 0.996,0.112,<0.001$; and $0.999,0.058,<0.001$. The derivative of the chosen polynomial third-degree function, expressing the instantaneous acceleration of the PWV, was then calculated. Thanks to the derivative, the number of
Correspondence: Luca Gabutti Department of Internal Medicine and Nephrology, Bellinzona Regional Hospital, Via Ospedale 6500 Bellinzona, Switzerland

Tel +4I 9I 8II 8464

Email luca.gabutti@eoc.ch 
days necessary at different ages to obtain the same progression of PWV as in 1 year at the age of 20 (considered in the calculations as the reference) was estimated. The cumulative relative age in year equivalents (considering the progression of PWV in 1 year at 20 years of age as a 1 -year equivalent) was finally calculated.

\section{Results}

Combining the data of the three abovementioned studies, ${ }^{3-5}$ we obtained a pooled population of 3,724 subjects classified in five age groups. The resulting mean PWV data are depicted in Figure 1A, where the polynomial curve describing the increase in PWV is superimposed on the original published data. The obtained polynomial function and its derivative (expressing the instantaneous PWV acceleration) were $f(x)=0.00004 x^{3}-0.0037 x^{2}+0.1646 x+4.0881$ and $f^{\prime}(x)=0.0001 x^{2}-0.0074 x+0.1646$, respectively. The number of days (if 365 at 20 years) necessary at 30, 50, and 65 years to produce the same amount of PWV progression obtained in 1 year at 20 is 318,170 , and 85 , respectively (Figure 1B for details). In other words, as a 65-year old, on March 26 of the current year, you will reach the same amount of vascular aging as after 1 year at 20 years of age; while as a 50-year old, you will have accumulated the same vascular changes on June 19. Figure 1C depicts the cumulative relative age calculated in year equivalents, considering the progression of PWV in 1 year at 20 years of age, as a 1 -year equivalent.

\section{Discussion}

The age-related increase in PWV does not follow a kinetic of constant acceleration and, between 20 and 69 years of age, is better approximated by a third-degree polynomial function. This means that vascular aging processes accelerate
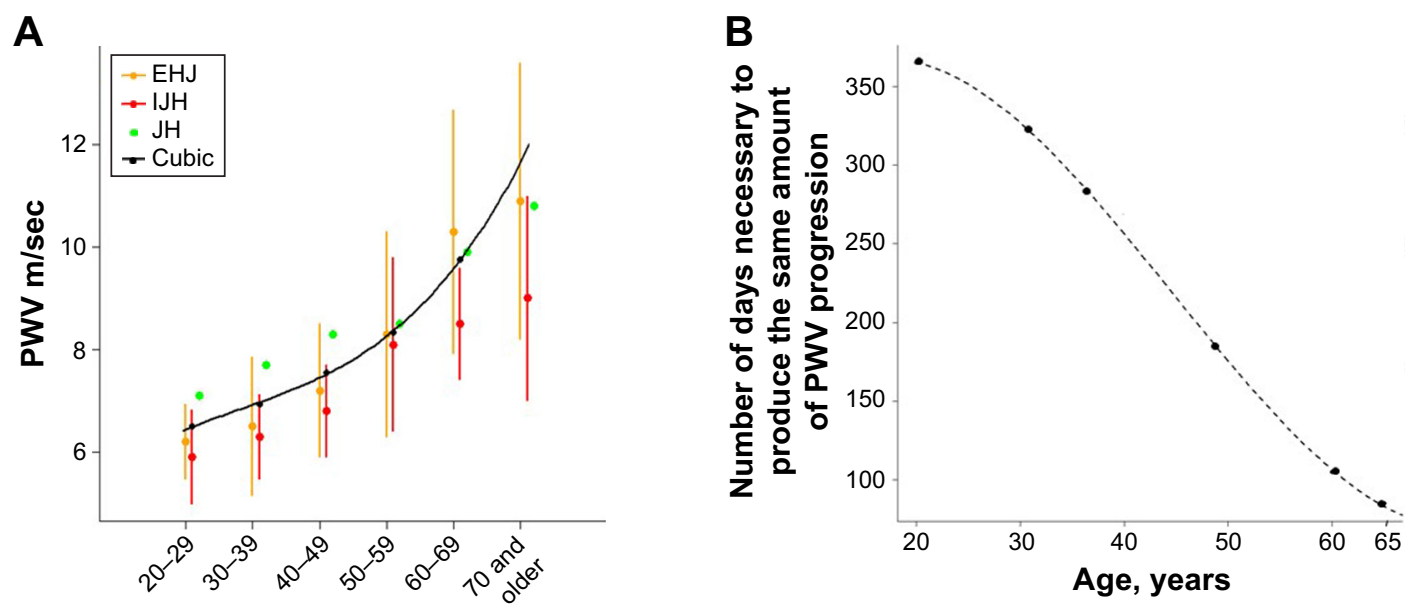

Age, years

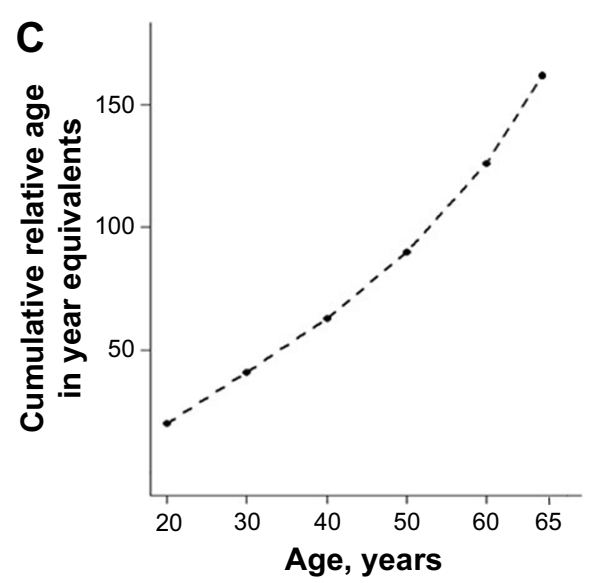

Figure I (A) Mean PWV data obtained combining the three populations $\left(\mathrm{EHJ}^{3}, \mathrm{IJH}^{4}, \mathrm{JH}^{5}\right)$ and polynomial cubic curve describing the course of the PWV progression superimposed on the original published data. (B) Polynomial cubic curve $\left(f(x)=0.0036 x^{3}-0.4852 x^{2}+13.677 x+254.8\right.$ ) describing the number of days (if 365 at 20 years) necessary at different ages to produce the same amount of PWV progression obtained in I year at age 20. (C) Polynomial cubic curve describing the cumulative "relative" age in year equivalents if the $\mathrm{I}$-year change in PWV at age 20 is used as a reference to calculate the flow of time.

Abbreviations: PWV, pulse wave velocity; EHJ, European Heart Journal; IJH, International Journal of Hypertension; JH, Journal of Hypertension. 
following a cubic function. As a consequence, comparing with the age of 20 , the same amount of structural changes influencing PWV will be obtained in half of the time at 50 and in a quarter of the time at 65 . The behavior of the PWV curve can be translated into two specular concepts: shorter time at later ages to reach the same amount of vascular structural changes obtained in 1 year at 20 (Figure 1B), or more, "relative" years of life, if the 1-year change in PWV at 20 is used as the reference to calculate the flow of time (Figure 1C). The subjective perception, confirmed in clinical studies, ${ }^{6}$ that time is running ever faster, however, supports the relationship highlighted in Figure 1B.

Nevertheless, we have to state that even if aortic PWV has the highest predictive value for cardiovascular prognosis, ${ }^{7}$ other markers of arterial stiffness like the augmentation index and the augmentation pressure do not follow the same kinetic. ${ }^{8,9}$ Furthermore, the absence of fit in our model of the age group older than 70 expresses an already known deceleration of the PWV progression in the last decades of life, and translates at least partially adaptive mechanisms related to age into the geometry and structure of the vessels. ${ }^{10}$

What remains to be investigated is whether or not the individual kinetic of the PWV progression correlates with the subjective perception of the time flow.

\section{Disclosure}

The authors report no conflicts of interest in this work.

\section{References}

1. Nilsson PM, Boutouyrie P, Cunha P, et al. Early vascular ageing in translation: from laboratory investigations to clinical applications in cardiovascular prevention. J Hypertens. 2013;31(8):1517-1526.

2. Kotsis V, Stabouli S, Karafillis I, Nilsson P. Early vascular aging and the role of central blood pressure. J Hypertens. 2011;29(10):1847-1853.

3. Cunha PG, Cotter J, Oliveira P, et al. Pulse wave velocity distribution in a cohort study: from arterial stiffness to early vascular aging. J Hypertens. 2015;33(7):1438-1445.

4. Díaz A, Galli C, Tringler M, Ramírez A, Cabrera Fischer EI. Reference values of pulse wave velocity in healthy people from an urban and rural Argentinean population. Int J Hypertens. 2014;2014:653239.

5. Mattace-Raso F, Hofman A, Verwoert GC, et al; Reference Values for Arterial Stiffness' Collaboration. Determinants of pulse wave velocity in healthy people and in the presence of cardiovascular risk factors: 'establishing normal and reference values'. Eur Heart J. 2010;31(19): 2338-2350.

6. Ferreira VF, Paiva GP, Prando N, Graça CR, Kouyoumdjian JA. Time perception and age. Arq Neuropsiquiatr. 2016;74(4):299-302.

7. London GM, Pannier B. Arterial functions: how to interpret the complex physiology. Nephrol Dial Transplant. 2010;25(12):3815-3823.

8. Lee HY, Oh BH. Aging and arterial stiffness. Circ J. 2010;74(11): 2257-2262.

9. Fantin F, Mattocks A, Bulpitt CJ, Banya W, Rajkumar C. Is augmentation index a good measure of vascular stiffness in the elderly? Age Ageing. 2007;36(1):43-48.

10. Humphrey ID, Harrison DG, Figueroa CA, Lacolley P, Laurent S. Central artery stiffness in hypertension and aging. Circ Res. 2016;118: 379-381.
Clinical Interventions in Aging

\section{Publish your work in this journal}

Clinical Interventions in Aging is an international, peer-reviewed journal focusing on evidence-based reports on the value or lack thereof of treatments intended to prevent or delay the onset of maladaptive correlates of aging in human beings. This journal is indexed on PubMed Central, MedLine,

\section{Dovepress}

CAS, Scopus and the Elsevier Bibliographic databases. The manuscript management system is completely online and includes a very quick and fair peer-review system, which is all easy to use. Visit http://www.dovepress. com/testimonials.php to read real quotes from published authors. 